\title{
Immobilization of urease enzyme on nanoceria modifies secondary and tertiary protein structures
}

\author{
Al-Hakeim Hussein Kadhem ${ }^{a}$, Khudhair Muneer Kadhem ${ }^{a}$, \\ Grulke Eric Anderson ${ }^{b}$ \\ ${ }^{a}$ College of Science, Faculty of Science, Kufa University, Iraq \\ ${ }^{b}$ College of Materials and Chemicals Engineering, University of Kentucky, USA \\ headm2010@yahoo.com
}

\begin{abstract}
Urease catalyzes the hydrolysis of urea to form ammonia and carbon dioxide. The increase in $\mathrm{pH}$ from the urease reaction causes a broad range of deleterious effects. Nanoceria (cerium oxide) possesses unique chemical properties under a redox reaction. This study investigated the synthesis of nanoceria via a hydrothermal method and determined its interaction with urease enzyme.

Transmission electron microscopy results showed a cubic-figured nanoceria with a size of $\sim 15 \mathrm{~nm}$. Urease was immobilized on nanoceria through adsorption. The maximum velocity $\left(V_{\max }\right)$ and Michaelis constant $\left(K_{\mathrm{m}}\right)$ of the free urease and urease immobilized on nanoceria decreased after interaction with nanoceria, and the Lineweaver-Burk plot showed an uncompetitive inhibition. The thermodynamic study of the adsorption process showed an endothermic reaction. The interaction changed the secondary and tertiary structures of urease as demonstrated by the circular dichroism study (the decrease in both $\alpha$ - and $\beta$-structure percentages). The fluorescence study revealed a change in the tertiary structure. The FTIR for the nanoceria-urease complex showed no changes in the covalent bonds, which indicated the involvement of physical forces in the interaction between urease and nanoceria.
\end{abstract}

Keywords: Nanoceria, protein structure, adsorption, urease, and circular dichroism.

\section{Introduction}

Urease (EC.3.5.1.5) is a nickel-dependent enzyme that catalyzes the hydrolysis of urea to form ammonia and carbon dioxide that is accompanied by an increase in $\mathrm{pH}$ (Follmer, 2008). Urease is produced by bacteria (numerous taxonomically diverse bacterial species), including normal flora and pathogens, as well as fungi, yeasts, and plants (Jones et al., 1990).

The increasing demand for clinical diagnostics related to kidney and liver diseases has necessitated the evolution of new methods for faster and more accurate estimation of urea in urine and blood samples. On the other hand, the increase in $\mathrm{pH}$ from the urease reaction causes a broad range of deleterious effects. In humans, urease is directly involved in the formation of infectious kidney stones (Mobley et al., 1989) and contributes to the pathogenesis of urolithiasis and pyelonephritis (Lodhi et al., 2006).

Nanoparticles have significant adsorption capacities because of their relatively large specific surface areas. Nanoparticles can bind or carry other molecules, such as chemical compounds, drugs, probes, and proteins, attached to the surface through covalent bonds or adsorption. The physicochemical properties of nanoparticles, such as charge and hydrophobicity, can be altered by attaching specific chemical compounds, peptides, or proteins to the surface (Aili et al., 2008; Jain, 2008).
The binding of proteins on active surfaces induces conformational changes at secondary and tertiary structure levels (Shang et al., 2007; Wu and Narsimhan, 2008). The protein adsorption on the nanoparticle surface affects protein structure and function (Shang et al., 2007; Wu and Narsimhan, 2008).

Nanoceria (cerium oxide nanoparticles) has many applications in biological systems. For example, nanoceria scavenges reactive oxygen species, functions as antioxidant, and prolongs the lifespan of mixed brain cell cultures (Rzigalinski, 2005). Nanoceria can protect cells from free radicalmediated injury and chemical activities. Nanoceria can interact with harmful radiation and protect normal cells from radiation (Korsvik et al., 2005). These findings indicate that nanoceria is a potential candidate for antioxidant and radioprotective applications (Wang et al., 2012). Therefore, determining the possible interaction between nanoceria and different proteins is important. In the present research, the interaction between nanoceria and urease was investigated.

\section{Methods and Materials}

\section{Synthesis of ( $15 \mathrm{~nm})$ nanoceria}

Ceria $\left(\mathrm{CeO}_{2}\right)$ with a particle size of $\sim 15 \mathrm{~nm}$ was synthesized via a hydrothermal method based on 
the following procedure (Tok et al., 2007). Briefly, $1.736 \mathrm{~g}$ of $\mathrm{Ce}(\mathrm{NO})_{3} \cdot 6 \mathrm{H}_{2} \mathrm{O}$ was dissolved in $10 \mathrm{~mL}$ of water. Subsequently, $0.16 \mathrm{~mol} / \mathrm{L} \mathrm{NaOH}$ was added dropwise into the solution (cold solutions) with stirring for 30 minutes and then heated in a vacuum oven at $174^{\circ} \mathrm{C}$ to $176^{\circ} \mathrm{C}$ for $24 \mathrm{~h}$. The mixture was cooled overnight. The mixture was then washed for three times with water, two times with ethanol, and once with water again. The suspension was transferred into a watch glass and placed in an oven at $40{ }^{\circ} \mathrm{C}$ overnight until completely dried. Transmission electron microscopy (TEM) was used to visualize the morphology and size of the prepared nanoceria.

\section{Interaction of urease with nanoceria}

Type III powder (15,000-50,000 units/gram solid) of urease (EC3.5.1.5, from Canavalia ensi formis or "jack beans") with a molecular weight of 480,000 Da was obtained from Sigma ${ }^{\circledR}$. Briefly, $2.5 \mathrm{~mL}$ of urease solution $(0.5,1,2,3,3.3,4,5$, and $6 \mathrm{mg}$ of urease $/ \mathrm{mL}$ of phosphate buffer) was mixed with $2.5 \mathrm{~mL}$ of nanoceria dispersion $(2 \mathrm{mg} / \mathrm{mL}$ ) for $60 \mathrm{~min}$ at room temperature. The mixture was centrifuged at 7,500 rpm for $45 \mathrm{~min}$ at $20{ }^{\circ} \mathrm{C}$, and the supernatant was separated. The concentration of urease (as protein) was determined spectrophotometrically at $595 \mathrm{~nm}$ (Bradford, 1976). Adsorption isotherm was constructed between the urease concentration at equilibrium $\left(C_{\mathrm{e}}\right)$ and the amount of urease that interact with the nanoparticles $\left(Q_{e}\right)$ to determine its optimal equation. Quantity adsorbed $\left(Q_{e}\right)$ can be calculated from the following formula:

$$
Q_{\mathrm{e}}=V\left(C_{\mathrm{o}}-\mathrm{C}_{\mathrm{e}}\right) / m
$$

where $C_{\mathrm{o}}$ is the initial concentration $(\mathrm{mg} / \mathrm{mL}), C_{\mathrm{e}}$ is the equilibrium concentration $(\mathrm{mg} / \mathrm{mL}), V$ is the volume of solution (mL), and $m$ is the weight of adsorbents $(\mathrm{mg})$. Thermogravimetric analysis of the nanoceria-urease complex was used to determine the loss of weight with the increase in temperature. Lost weight is supposed to be due to the degradation of the adsorbed urease.

\section{Urease activity}

Urease activity was determined by measuring the quantity of ammonia released per minute at room temperature and $\mathrm{pH}=7$. The working reagent was prepared by mixing $500 \mu \mathrm{l}$ of $1.65 \mathrm{mg} / \mathrm{mL}$ of urease: free, immobilized, or mixed with nanoceria (mixture of $1.65 \mathrm{mg} / \mathrm{mL}$ urease with $2 \mathrm{mg} / \mathrm{mL}$ nanoceria) with $30 \mathrm{~mL}$ of the solution containing $50 \mathrm{mmol} / \mathrm{L}$ phosphate buffer, $26 \mathrm{mmol} / \mathrm{L}$ sodium salicylate, $3.35 \mathrm{mmol} / \mathrm{L}$ sodium nitroprusside, and $1 \mathrm{mmol} / \mathrm{L}$ EDTA; $\mathrm{pH}=8$ ). Briefly, $25 \mu \mathrm{l}$ of differ- ent urea concentrations $(0.167,0.334,0.501,0.668$, $0.835,1.002,1.169,1.336,1.505$, and $1.67 \mathrm{mmol} / \mathrm{L})$ were mixed with $1 \mathrm{~mL}$ of the working reagent and then incubated for $5 \mathrm{~min}$ at room temperature. Subsequently, $200 \mu \mathrm{L}$ of the alkaline reagent $(0.5 \mathrm{mmol} / \mathrm{L}$ sodium hydroxide and $24.8 \mathrm{mmol} / \mathrm{L}$ sodium hypochlorite) was added. The mixture was incubated for 5 minutes, and the absorbance was determined using a spectrophotometer at $580 \mathrm{~nm}$. Kinetic parameters: $K_{\mathrm{m}}$ and $V_{\max }$ were calculated according to Michaelis-Menten equation by plotting $1 / v^{\circ}$ versus $1 /[S]$.

\section{Estimation of the change in urease structure after adsorption on nanoceria}

Circular dichroism (CD) spectra of free urease and nanoceria-urease complex after adsorption were obtained using Jasco CD spectrometer at $20{ }^{\circ} \mathrm{C}$ to determine the changes in the secondary structure of urease caused by the adsorption on nanoceria. Three scans were averaged using the Chirascan Pro-Data Viewer software. Thermal stability was examined by monitoring the changes in ellipticity at $22 \mathrm{~nm}$ as a function of temperature. Equipment parameters include a gradient from $20.0{ }^{\circ} \mathrm{C}$ to $99.0^{\circ} \mathrm{C}$ and a stepped ramping of $10^{\circ} \mathrm{C}$ per step.

The changes in the tertiary structure of urease after adsorption on nanoceria were determined via fluorescence spectrophotometry. The fluorescence emissions of free and adsorbed urease were determined from the spectra obtained using a Cary Eclipse fluorescence spectrophotometer with a scan speed of $600 \mathrm{~nm} / \mathrm{min}$. The emission spectra were scanned from 220-400 $\mathrm{nm}$ at room temperature. FTIR spectra of nanoceria, free urease, and immobilized urease were recorded using a Thermo Nicolet NeXus 470 FT-IR spectrometer with KBr as a diluting agent and operated within the range of $400-4000 \mathrm{~cm}^{-1}$.

\section{Estimation of thermodynamic parameters of urease adsorption}

The nanoceria-urease adsorption process was initiated by mixing $2 \mathrm{~mL}$ of $6 \mathrm{mg} / \mathrm{mL}$ urease solution with $2 \mathrm{~mL}$ of $2 \mathrm{mg} / \mathrm{mL}$ nanoceria. The solution was stirred for $60 \mathrm{~min}$ at different temperatures to determine the thermodynamic parameters (change in free energy $\Delta G$, enthalpy $\Delta H$, and entropy $\Delta S$ ) of the adsorption process (15, $25,35,45$, and $55^{\circ} \mathrm{C}$ ). After centrifugation, the urease concentration in the supernatant $\left(C_{\mathrm{e}}\right)$ was measured via Bradford method, and the precipitate (nanoceria-urease) was separated and used in the following desorption experiments. VantHoff's equation ( $\ln X_{\mathrm{m}}=-\Delta \mathrm{H}^{\circ} / R T+$ constant) was constructed to calculate the change in enthalpy 
where $\Delta \mathrm{H}^{\circ}$ : enthalpy in reaction, $X_{\mathrm{m}}$ : maximum amount adsorbed, and $R$ : gas constant equal to $8.314 \mathrm{~J} /$ mol.K. By plotting $\ln X_{\mathrm{m}}$ against $1 / T$, a straight line should be formed with a slope of $-\Delta \mathrm{H}^{\circ} / R$.

To determine the free energy change of the adsorption process at a specific temperature, we calculated the equilibrium constant of the adsorption process of urease on nanoceria by using

$$
K_{\mathrm{eq}}=\left(Q_{\mathrm{e}} \times m\right) /\left(C_{\mathrm{e}} \times V_{(\mathrm{mL})}\right)
$$

where $K_{\mathrm{eq}}$ : equilibrium constant, $Q_{\mathrm{Q}}$ : adsorption amount $(\mathrm{mg} / \mathrm{g}), m$ : mass of nanoceria $(\mathrm{mg}), C_{\mathrm{e}}$ : concentration of urease at equilibrium $(\mathrm{mg} / \mathrm{mL})$, and $V_{(\mathrm{mL})}$ : volume of the solution $(\mathrm{mL})$.

$$
\Delta \mathrm{G}^{\circ}=-R T \ln K_{\mathrm{eq}}
$$

where $\Delta \mathrm{G}^{\circ}$ : Gibbs free energy

$$
\Delta \mathrm{H}^{\circ}=\Delta \mathrm{G}^{\circ}-T \Delta \mathrm{S}^{\circ} .
$$

From the equations, the change in entropy can be calculated from the following equation:

$$
\Delta \mathrm{S}^{\circ}=\left(\Delta \mathrm{G}^{\circ}-\Delta \mathrm{H}^{\circ}\right) / T
$$

where $\Delta S^{\circ}$ : entropy of the reaction.

\section{Desorption procedure}

Briefly, $2 \mathrm{~mL}$ of phosphate buffer was added to the precipitate (nanoceria-urease) from thermodynamic experiments and mixed for $1 \mathrm{~h}$ at different temperatures (288, 298, 308, 318, and $328 \mathrm{~K})$. After centrifugation, the urease concentration in the supernatant $\left(C_{\mathrm{e}}\right)$ was measured via Bradford method, and the amount of adsorption was calculated using the following formula:

$$
\text { Percentage of desorption }=\left(Q_{2} / Q_{1}\right) \times 100 \%
$$

where $Q_{1}$ : quantity adsorbed on the nanoceria (quantity that immobilized initially on the nanoceria in the adsorption experiment) and $Q_{2}$ : quantity desorbed (released) to the solution.

\section{Results and Discussion}

Both size and morphology of the synthesized nanoparticles were confirmed via TEM, which demonstrated the cubic particles of nanoceria with dimensions of $\sim 15 \mathrm{~nm}$, as shown in the Fig. 1 .

TEM showed the cubic morphology of nanoceria after immobilization of urease on their surfaces; the morphology is shown in the right-hand picture. The morphology of the distribution of urease on the surface of nanoceria after adsorption confirms the presence of urease on the surface; the morphology is presented as a dark shadow compared with that of the free nanoceria in the left image.
TGA was used to ensure that the urease molecules are adsorbed by the nanoparticles regardless of the calculations (that is, weight loss from urease decomposition was used to confirm its existence on the surface of nanoceria). The TGA experiment for the nanoceria associated with urease showed some decoupling reactions on the surface of the nanoparticles with the increase in temperature. The main surface decoupling reaction is the decomposition of urease into its component (Wang et al., 2012). The lost weight corresponds to the amount of the urease adsorbed on nanoceria and is measured via Bradford method, which confirms the formation of the nanoceria-urease complex.

The optimal method to describe the interaction between urease and nanoparticles is the adsorption phenomenon. Protein adsorption is a very complex process driven by different protein-surface forces, including Van der Waals, hydrophobic, and electrostatic. Other processes, including structural rearrangements in the protein, dehydration of the protein and parts of the surfaces, redistribution of charged groups in the interfacial layer, and the function of small ions in the overall adsorption process, are also considered. Protein adsorption depends on the chemical and physical characteristics of the surface (Walczyk et al., 2010; Monopoli et al., 2011). Numerous studies assumed that proteins behave as rigid bodies, where no conformational changes occur during adsorption. However, this assumption is apparently incorrect. The conformational changes in proteins can contribute significantly to the driving force for adsorption. Proteins are highly ordered structures. The pattern of protein stability is necessary to assess the tendency of proteins to be adsorbed on surfaces. The optimal adsorption isotherm equation for describing the interaction between nanoceria and urease is the Sips equation (Figure 2); this equation is an empirical model for heterogeneous adsorption [Koutsopoulos et al., 2005]

$$
Q_{e}=Q_{\mathrm{m}} \times K_{\mathrm{S}} \times C_{\mathrm{e}}^{\mathrm{t}} / 1+K_{\mathrm{S}} \times C_{\mathrm{e}}^{\mathrm{t}}
$$

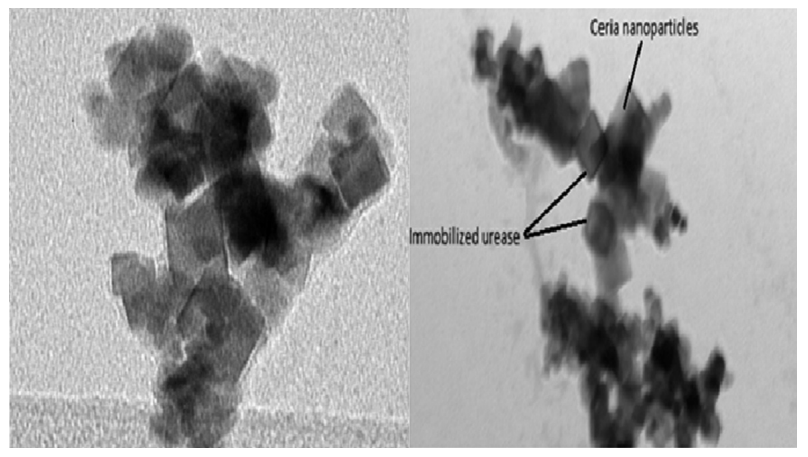

Fig. 1. TEM images for nanoceria (left image) and immobilized urease on nanoceria (right image). 


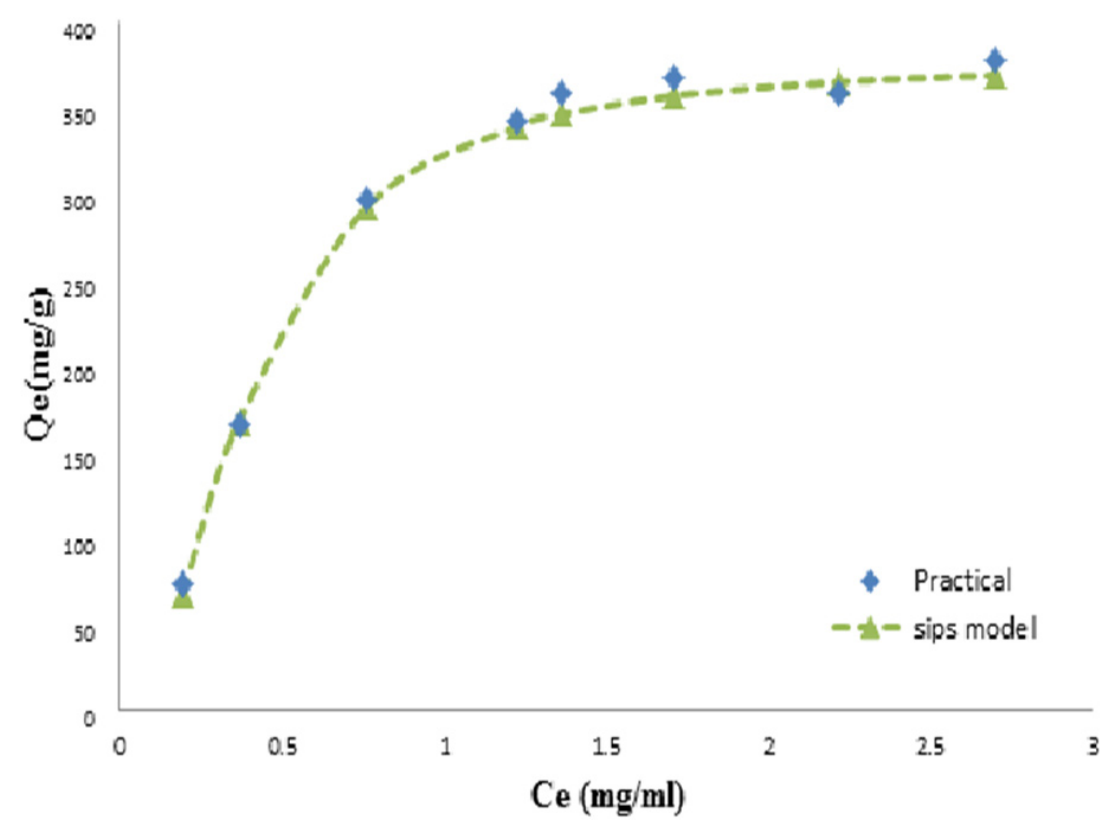

Fig. 2. Adsorption model for urease on nanoceria. Rhombi represent the practical results and the triangles represent theoretical Sips model.

where $Q_{e}$ is the adsorption amount normalized by the mass of nanoparticles, $Q_{\mathrm{m}}$ is the maximum adsorption capacity, $C_{\mathrm{e}}$ is the concentration of the adsorbent in the supernatant at adsorption equilibrium, $K_{\mathrm{S}}$ is a constant related to the adsorption energy, and $t$ is a heterogeneity coefficient.

The magnitude of $t$ is connected to the factors affecting heterogeneous adsorption. At $0<t<1$, heterogeneity is linked to the variations on the solid surface (that is, if $t$ is less than 1 , heterogeneity is assumed to reflect the surface heterogeneity itself). When the adsorbed molecule has a strong affinity to other adsorbent molecules (a positive cooperative effect), $t$ is higher than 1 (Wang et al., 2012). The energy distribution of protein adsorption on nanoparticles shows its heterogeneous behavior because of surface heterogeneity and the lateral effect between the adsorbed molecules (Wang et al., 2012). Urease contains four surfaces with exposed histidine and several cysteine residues. The presence of these residues affects the immobilization of urease via adsorption (Emre et al., 2011). Urease adsorption was low within the concentration range of $0.25-1.5 \mathrm{mg} / \mathrm{mL}$. However, an adsorption amount higher than $1.5 \mathrm{mg} / \mathrm{mL}$ increased rapidly with the increase in concentration and reached a plateau near $359.60 \mathrm{mg} / \mathrm{g}$. The two "limiting" orientations of urease on the surface are end-on or side-on. The "end-on" orientation prevails when adsorption occurs from a solution with high concentration, whereas a "side-on" orientation monolayer is observed at a low concentration.

The activity of urease enzyme in the presence of nanoceria, absence of nanoceria, and immobilized urease was presented using the Lineweaver-Burk plots, as shown in the Fig. 3.

Kinetic parameters $V_{\max }$ and $K_{\mathrm{m}}$, were calculated from the regression equation of each line and are presented in Table 1.

Tab. 1. Kinetic parameters of the free and immobilized urease.

\begin{tabular}{lcc}
\hline Enzyme type & $\begin{array}{c}V_{\max } \\
(\mu \mathrm{M} / \min )\end{array}$ & $\begin{array}{c}K_{\mathrm{m}} \\
(\mu \mathrm{M})\end{array}$ \\
\hline Free urease & 1557.6 & 5615.2 \\
Urease and nanoceria & 976.5 & 4309.6 \\
Immobilized urease & 695.9 & 3869.2 \\
\hline
\end{tabular}

Kinetic parameters were calculated from data shown in the Fig. 3.

Figure 3 shows the reduction in the $V_{\max }$ and $K_{\mathrm{m}}$ of urease in the presence of nanoceria $(\mathrm{p}=0.038)$ and of the immobilized urease $(\mathrm{p}=0.027)$ compared with that of the free urease. These differences and the shape of the lines in Fig. 3 indicate that urease enzyme is exposed to an uncompetitive inhibitor. In the present study, the Michaelis constant $\left(K_{\mathrm{m}}\right)$ (Tab.1) of the urease enzyme is within the normal range in the literature (Toth, 2002). The physical and chemical properties of enzymes and the method of determination reveal that the $K_{\mathrm{m}}$ for the urease of plants ranges from $1.3 \mathrm{mmol} / \mathrm{L}$ to $33 \mathrm{mmol} / \mathrm{L}$ (Toth, 2002). The decrease in the $V_{\max }$ of the urease caused by the formation of the inhibitor-enzyme complex decreases the formation of the enzyme-substrate complex (Toth, 2002). In the present study, urease enzyme can be attached 


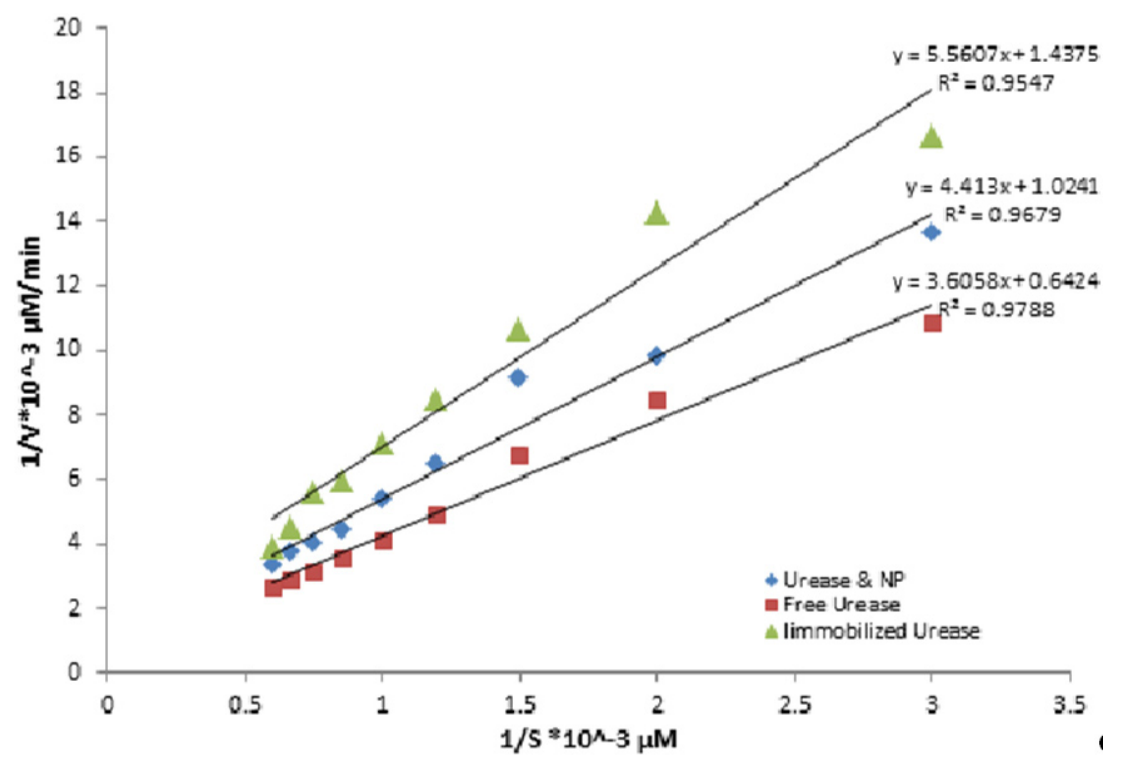

Fig. 3. Lineweaver-Burke plots for the activity of free urease, immobilized urease, and mixture of nanoceria and urease. Rhombi - urease with nanoparticles, squares - free urease, and triangles - immobilized urease.

to the surface of nanoceria through various types of forces, which mainly include physical forces, such as van der Waals, dipole-dipole, H-bonding, and electrostatic forces; this finding is consistent with the results from previous studies (Walczyk et al., 2010; Monopoli et al., 2011). The adsorption of protein to the surface may induce conformational changes in the protein. Binding occurs between the different domains of the urease molecules and the surface of nanoceria; this binding may affect the interaction between the urea and the urease enzyme and subsequently decreases the enzyme activity. Therefore, the inhibition effect of nanoceria caused by the forces between the urease and the surface reduces the activity of the immobilized urease enzyme instead of the inhibition processes; thus, the three-dimension structure of urease changes after binding to the surface through different forces (Lai and Tabatabai, 1992). Numerous studies found that activity reduction is related to the loss of $\alpha$-helical content when proteins are adsorbed onto nanoparticles regardless of an increase in the $\beta$-sheet (Shang et al., 2007; Jain, 2008).

Results demonstrate that nanoceria can partially inhibit the urease enzyme. However, the enzyme does not lose all activity and is active even in the immobilized state. This finding can be used in particular medical and industrial applications that require an easy separation for the immobilized enzyme from aqueous medium (Kleijn and Norde, 1995). Urease inhibitors are important in eradicating the infection caused by urease-producing bacteria. In this context, the selected inorganic salts, heavy metal ions, synthetic organic compounds, and antibiotics are used as specific urease inhibitors (Hearn and Neufeld, 2000).

The changes in the secondary structure of urease after adsorption on nanoceria were analyzed via CD spectroscopy, which is particularly efficient in determining the protein folding and in characterizing the secondary structure of protein and denaturant stabilities (Amin et al., 2010). The secondary structure can be determined via CD spectroscopy in the far-UV spectral region (200-260 nm), and the chromophore at this wavelength is the peptide bond. The CD spectra for the free and immobilized urease on nanoceria are presented in the Fig. 4.

The CD results were analyzed using the K2D2 web server to determine the change in the urease secondary structure from the CD spectra according to the published software (Koutsopoulos et al., 2005). The results showed that the secondary structure of the free urease consists of $84.27 \% \alpha$-helix and $1.24 \%$ $\beta$-sheet, whereas the remainder is random coil. This structure significantly changes after immobilization of urease. The percentages of the secondary structure components consist of $28.35 \% \alpha$-helix and $11.53 \% \beta$-sheet, whereas the remainder is random coil. The significant change in the secondary structure indicates that the adsorption of urease on nanoceria involves a contact with the domains rich in alpha structures on the urease molecule surface. These results are confirmed by the reduced activity of urease enzyme when adsorbed on nanoceria, as shown in Tab. 1 and Fig. 3.

To study the thermal stability of urease when adsorbed on nanoceria, we measured the ellipticities as a function of temperature. Fig. 5 shows the CD 


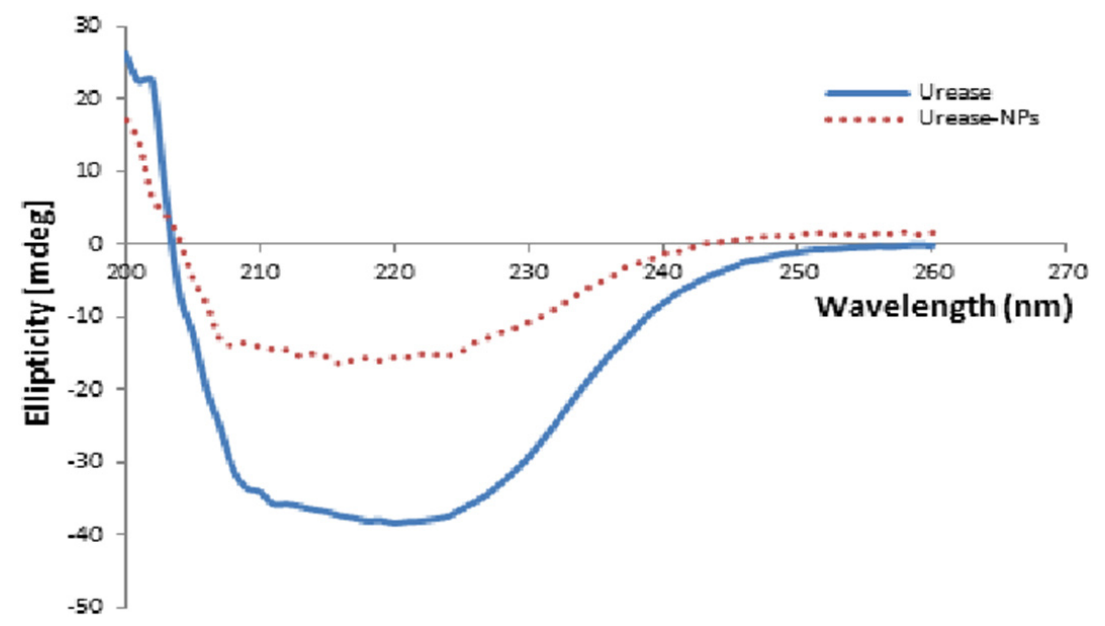

Fig. 4. CD for the free and immobilized urease. Dotted line represents urease-nanoparticle composite and continuous line represents free urease.

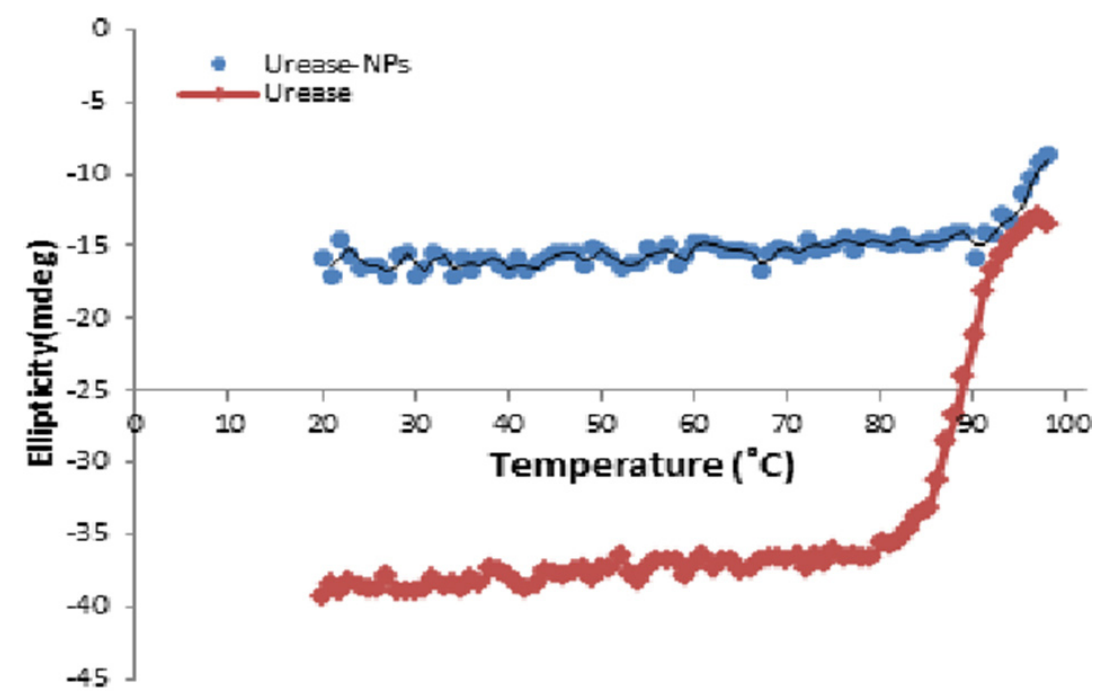

Fig. 5. CD spectra of free and adsorbed urease as a function of temperature.

spectra of the free urease and nanoceria-urease complex at different temperatures. CD illustrates the disruption of the secondary structural elements upon increasing the thermal processing of urease (Iratxeta and Navarro, 2008). The maximum temperature reached is $80^{\circ} \mathrm{C}$ as shown in Fig. 5, and the free urease still shows a normal structure.

The maximum temperature that the equipment can reach is $90^{\circ} \mathrm{C}$ as shown in Fig. 5, and the immobilized urease still shows a normal structure and thus may not be completely denatured. These results indicate that the immobilized urease has more thermostability than the free urease. In both cases, the negative ellipticity at $220 \mathrm{~nm}$ decreases; a decrease in rigidity occurs when the sample temperature increases, which leads to the irreversible denaturation of the protein. The structural changes in protein molecules directly affect their biological functions, which is the most intriguing aspect of protein adsorption from theoretical and practical points of view (Lee et al., 1990; Iratxeta and Navarro, 2008). Fluorescence spectroscopy was used to monitor the changes in the tertiary structure of the protein. The three amino acids with intrinsic fluorescence properties are phenylalanine, tyrosine, and tryptophan. However, only tryptophan was used experimentally because the quantum yields (emitted photons/excited photons) of tryptophan are sufficiently high to achieve good fluorescence signal. Therefore, this technique is limited to the proteins with tryptophan. These residues can be used to follow the protein folding because fluorescence properties (quantum yields) are sensitive to the environment, which changes when the protein folds/unfolds (Carter et al., 2011).

The fluorescence emission of the free and adsorbed urease was determined from the spectra obtained using a Cary Eclipse fluorescence spectrophoto- 
meter. Fluorescence quenching studies were used to monitor the tryptophan environment of urease when interacting with nanoceria, as shown in Fig. 6 .

The peak of the fluorescence emission of the free urease and the urease dispersed on nanoceria was at $360 \mathrm{~nm}$. The change in the spectra may be due to the change in the environment polarity of the protein or the environment surrounding the tryptophan residues, which may be buried in the hydrophobic core of proteins; these changes result in a shift by $10 \mathrm{~nm}$ to $20 \mathrm{~nm}$ compared with those on the surface of the protein (Myers, 1988). After interaction with nanoceria, the intensity of urease spectrum decreases because of the changes in its tertiary structure (Caputo and London, 2003).

To determine the types of bonds included in the tertiary structure, we performed FTIR for the free and adsorbed urease on nanoceria in addition to nanoceria only. Chart (a) in Fig. 7 shows that the free urease consists of several functional groups and includes the appearance peak at $1100 \mathrm{~cm}^{-1}$, which corresponds to the $\mathrm{C}-\mathrm{O}$ of carboxylic acid (Meyers, 2000); a $\mathrm{C}=\mathrm{O}$ stretch of peptide bond at $1650 \mathrm{~cm}^{-1}$ is generally used for the structural analysis of protein (Meyers, 2000; Brown, 2009), whereas the region between $3000-3500 \mathrm{~cm}^{-1}$ contains overlapping broad peaks, including $\mathrm{O}-\mathrm{H}, \mathrm{N}-\mathrm{H}$ stretch, and $\mathrm{C}-\mathrm{H}$ stretch groups (Meyers, 2000). Curve (b) shows a decrease in the signal of the absorbance of the FT-IR spectra for the immobilized urease compared with that of the free urease; this finding suggests that adsorption decreases the amount of urease. Moreover, a significant loss was observed in the intensity of band $\left(1100 \mathrm{~cm}^{-1}\right)$, which refers to the interaction of a large number of the $\mathrm{CO}$ groups of urease with nanoceria; this region is where urease bonds with nanoceria. Thus, $\mathrm{CO}$ groups are sites on urease molecules where adsorption to nanoceria occurs. However, the breakdown or formation of new covalent bonds after the interaction of urease with nanoparticles has no evidence (Fig. 7 (a) and (b)) (Chinkap and Myunghee, 2004). Therefore, the forces in adsorption process include physical forces, such as Van der Waals, hydrophobic interactions, dipole-dipole, ion-dipole, and hydrogen bonding; however, covalent bonding is not included.

To determine the thermodynamics for the adsorption of urease on nanoceria, we performed the adsorption process at different temperatures (288, 298, 308, 318, and 328 K). First, enthalpy change is calculated using the plot of Vant-Hoff's equation presented in Fig. 8.

The positive value of $\Delta \mathrm{H}^{\circ}\left(3.49 \mathrm{~kJ} \cdot \mathrm{mole}^{-1}\right)$ indicates that the adsorption process is endothermic. The values of the changes in free energy and entropy are presented in Tab. 2.

The values of $\Delta G^{\circ}$ and $\Delta S^{\circ}$ minimally change with increasing temperature, as shown in Tab. 2. A negative value for $\Delta \mathrm{G}^{\circ}$ indicates that the interaction can be spontaneous, whereas $\Delta S^{\circ}$ represents the change in thermodynamic functions. Protein adsorption can be driven by entropy changes, particularly if the adsorption is endothermic. The positive value of $\Delta \mathrm{S}^{\circ}$ indicates that the product is more random than the reactants (urease and nanoceria). The changes in entropy occur

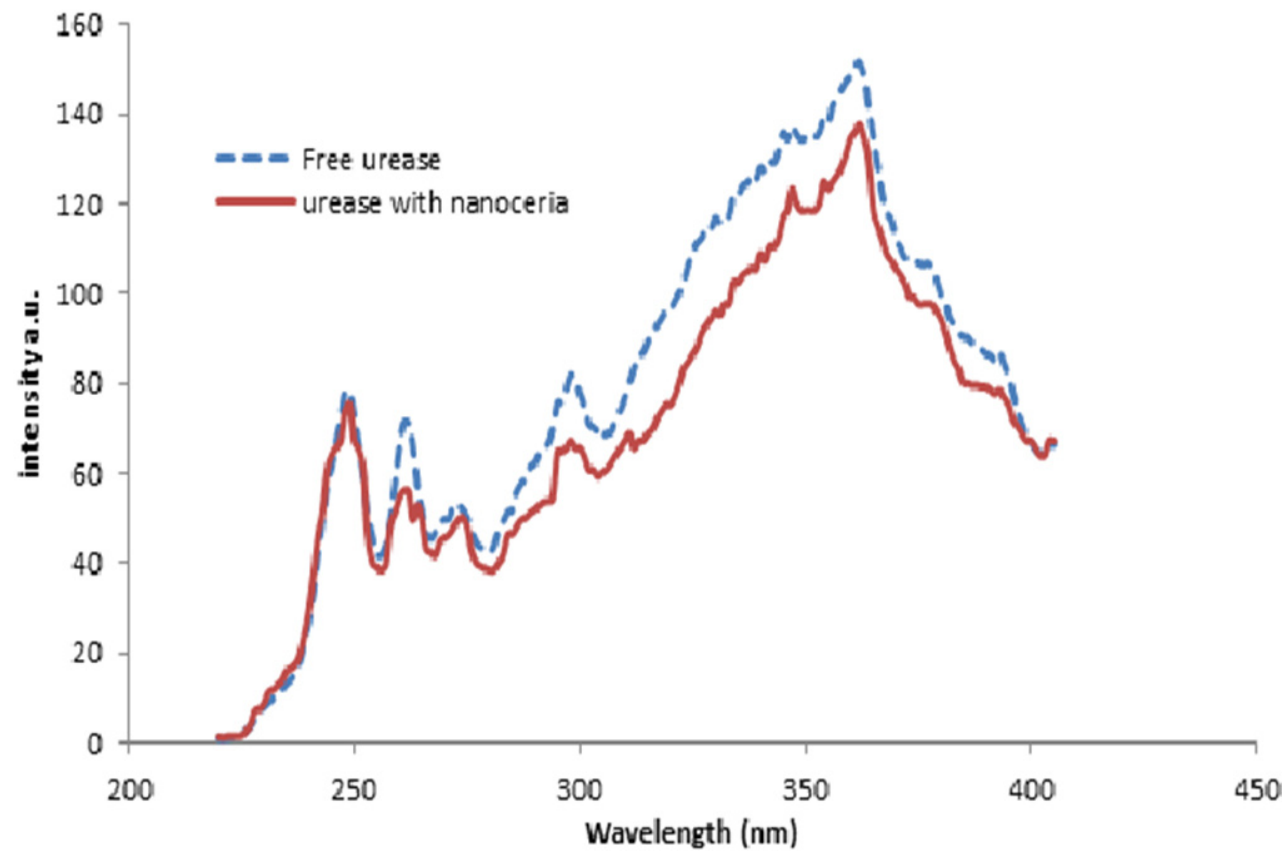

Fig. 6. Fluorescence spectra of the free and immobilized urease. 


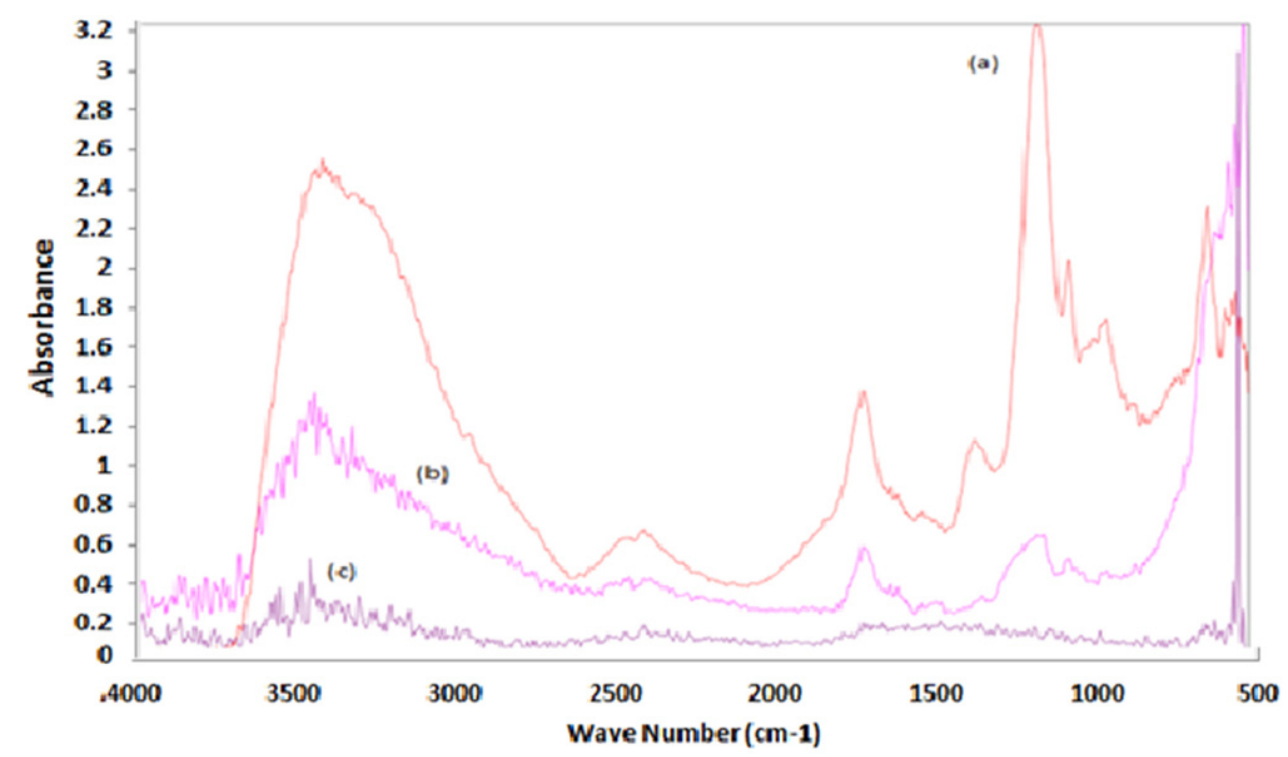

Fig. 7. FTIR chart for (a) free urease (b) immobilized urease on ceria, and (c) nanoceria only.

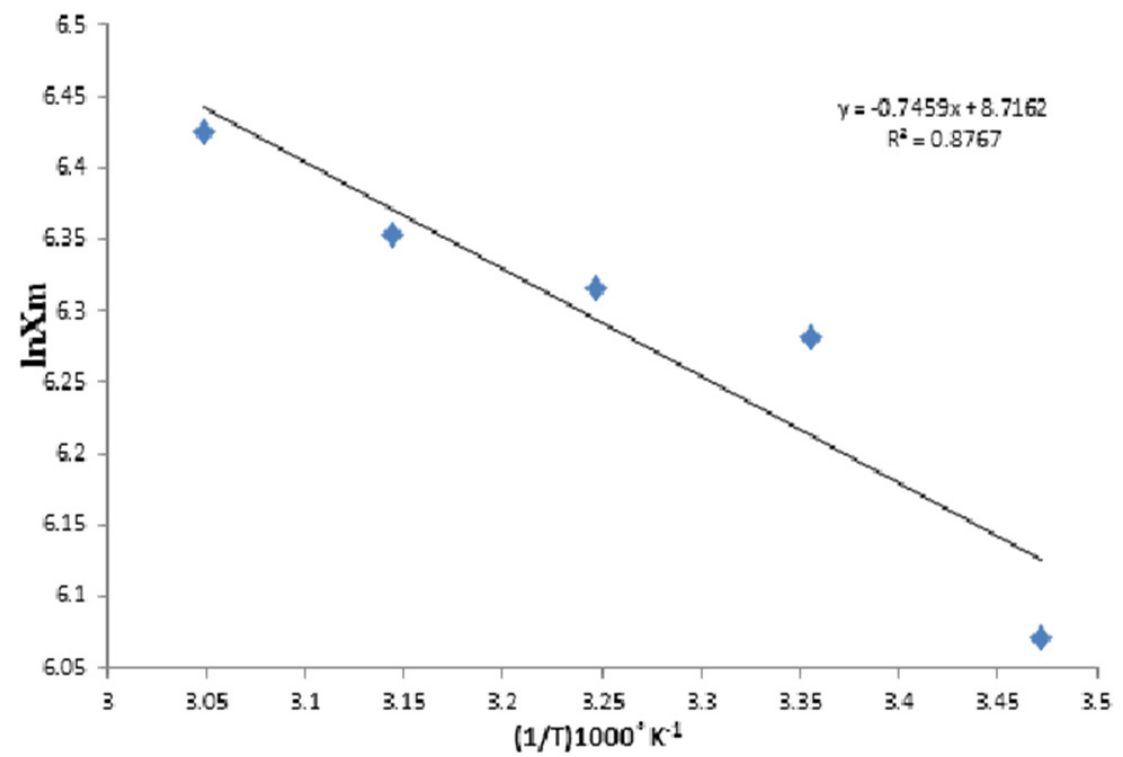

Fig. 8. Vant-Hoff's plot of the adsorption of urease on nanoceria.

Tab. 2. Thermodynamic parameters of the adsorption process of urease on nanoceria at different temperatures.

\begin{tabular}{cccc}
\hline $\begin{array}{c}\Delta \mathrm{H}^{\circ} \\
\left(\mathrm{kJ} \cdot \mathrm{mole}^{-1}\right)\end{array}$ & $\begin{array}{c}\mathrm{T} \\
(\mathrm{K})\end{array}$ & $\begin{array}{c}\Delta \mathrm{G}^{\circ} \\
\left(\mathrm{kJ} \cdot \mathrm{mole}^{-1}\right)\end{array}$ & $\begin{array}{c}\Delta \mathrm{S}^{\circ} \\
\left(\mathrm{J} \cdot \mathrm{mole}^{-1} \mathrm{~K}^{-1}\right)\end{array}$ \\
\hline 3.49 & 288 & -3.94 & 25.8 \\
& 298 & -4.45 & 26.7 \\
& 308 & -4.68 & 26.5 \\
& 318 & -4.91 & 26.4 \\
& 328 & -5.23 & 26.6 \\
\hline
\end{tabular}

$\mathrm{T}=$ Temperature, $\Delta \mathrm{H}^{\circ}=$ Enthalpy, $\Delta \mathrm{G}^{\circ}=$ Free energy change, and $\Delta \mathrm{S}^{\circ}=$ Entropy. because of the dehydration of the hydrophobic parts of the ceria surface and the freedom given to the molecule by the structural changes in the proteins (Kleijn and Norde, 1995). Nanoceria has a positive charge, and urease has a net positive charge at pH 7 (Marzadori et al., 1998). Robertson and Zydney (1990) reported that proteins can be adsorbed on the surfaces with similar charges. However, majority of the samples reveal that electrostatic interaction is the main driving force for protein adsorption (Robertson and Zydney, 1990). Moreover, when the bond formed is electrostatic, a negative $\Delta \mathrm{G}^{\circ}$ refers to strong electrostatic bonds (Jing et al., 2010). 


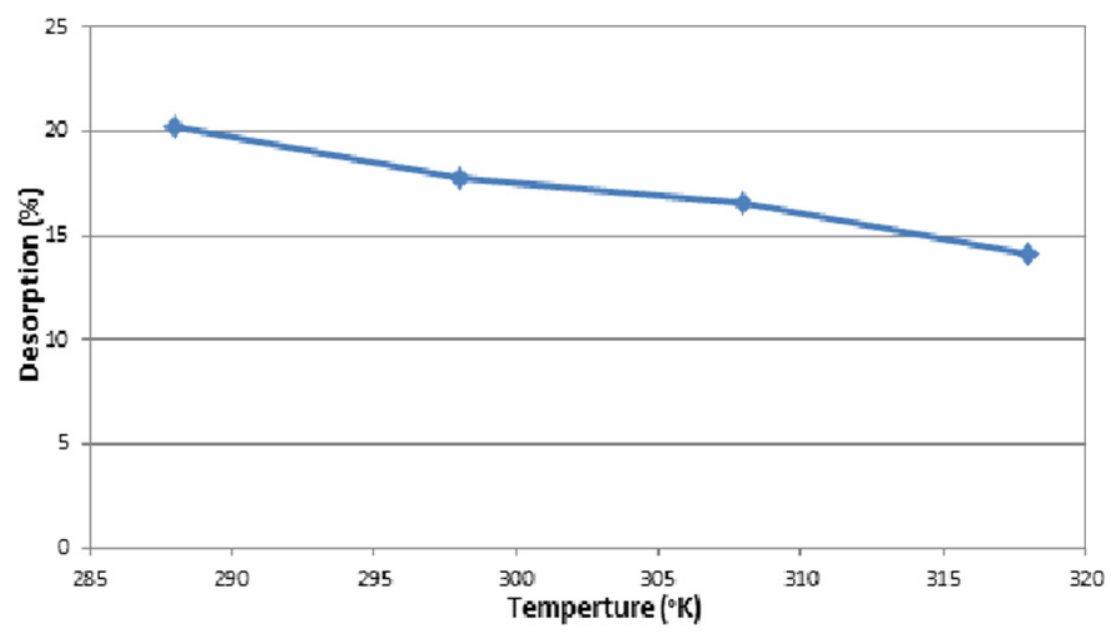

Fig. 9. Desorption of urease from nanoceria surface at different temperatures.

\section{Desorption}

The removal of the enzyme from the surface of nanoparticles increases with the decrease in temperature, as shown in the Fig. 9. This finding suggests that bond formation between the enzyme and nanoparticles is weak; this bond can be broken via the dilution process by adding a volume of solvent to the nanoceria-urease complex. The urease desorption capacity from nanoceria can be repeatedly used in enzyme immobilization without any detectable losses in their initial adsorption capacities and activities (Emre et al., 2011).

The adsorbed proteins on the surface can be removed by changing the $\mathrm{pH}$, temperature, and ionic strength, as well as by adding low-molecular-weight substances, such as electrolytes, or by adding a displacer (exchange against dissolved proteins) (Norde et al., 1986). Protein desorption is related to the hydrophobicity of the sorbent surface. Desorption is larger when surface coverage is high because of the heterogeneous part of the sorbent surface (the most favorable adsorption sites are occupied at first) (Norde et al., 1986; Emre et al., 2011).

\section{Conclusion}

Enzyme inhibition is a vital research area. The results indicated that urease adsorption process inhibited the activity of urease, and the decreased values of $K_{\mathrm{m}}$ and $V_{\max }$ suggested an uncompetitive inhibition. Moreover, the enzyme still worked even if immobilized on nanoceria. The adsorption of urease on the surface of nanoceria was weak based on the thermodynamic values and the minimal amount of adsorption. The results also showed that the adsorption of urease on nanoceria changed the secondary and tertiary structure components. The urease removed from nanoceria through desorption had weak interaction forces with nanoceria.

\section{References}

Aili D, Enander K, Rydberg J, Nesterenko I, Bjorefors F, Baltzer L, Liedberg B (2008) J Am Chem Soc. 130: 5780-5788.

Amin M, Iqbal MS, Hughes RW, Khan SA, Reynolds PA, Enne VI, Rahman S, Mirza AS (2010) J Enzyme Inhib. Med. Chem. 25: 383-3890.

Bradford MM (1976) Anal. Biochem. 72: 248-254.

Brown I (2009) A thesis submitted to the University of Birmingham, UK for the degree of $\mathrm{PhD}$ in Chemical Engineering.

Caputo GA, London E (2003) Biochemistry 42: 32753285.

Carter EL, Tronrud DE, Taber SR, Karplus PA, Hausinger RP (2011) Proc. Natl. Acad. Sci. USA. 108: 13095-13099.

Chen Y, Barkley MD (1998) Biochemistry. 37: 99769982.

Chinkap C, Myunghee L (2004) Bull. Korean Chem. Soc. 25: 1461-1462.

Emre Ç, Mehmet S, Fatih A (2011) Afric. J. Biotech. 10: 6590-6597.

Follmer C (2008) Phytochemistry 69: 18-28.

Hearn E, Neufeld RJ (2000) Process Biochem. 35: $1253-1260$.

Jain KK, (2008) Med. Principles Pract. 1789-1801.

Jing LV, Yongjun J, Qingsen YU (2010) Eur. J. Biochem. 16: $125-135$.

Jones BD, Lockatell CV, Johnson DE, Warren JW, Mobley HL (1990) Infect. Immun. 58: 1120-1123.

Kleijn M, Norde W (1995) Heterog. Chem. Rev. 2: $157-172$

Korsvik C, Patil S, Seal S (2005) Anal. Chem. 77: 2157-2165.

Koutsopoulos S, Tjeerdsma AM, Lieshout JFT, van der Oost J, Norde W (2005) Biomacromolecules 6: 1176-1184.

Lai CM, Tabatabai MA (1992) Soil Biol. Biochem. 24: 225-228.

Lee MH, Mulrooney SB, Hausinger RP (1990) J. Bacteriol. 172: 4427-4431.

Lodhi MA, Hussain J, Abbasi MA, Jassbi AR, Choudhary MI, Ahmad VU (2006) J Enzyme Inhib. Med. Chem. 21: 531-535. 
Marzadori C, Miletti S, Gessa C, Ciurli S (1998) Soil Biol. Biochem. 30: 1485-1490.

Meyers RA (2000) In Encyclopedia of Analytical Chemistry, John Wiley \& Sons Ltd, Chichester, 10815-10837.

Mobley HL, Hausinger RP (1989) Microbiol. Rev. 53 85-103.

Monopoli MP, Walczyk D, Campbell A, Elia G, Lynch I, Bombelli F et al. (2011) J. Am. Chem. Soc. 133: 2525-2534.

Myers C (1988) In Characterization of proteins, ed F. Franks. Humana Press, Clifton, NJ, 491-451.

Norde W, MacRitchie F, Nowicka G (1986) J. Colloid Interface Sci. 112: 447-456.

Perez-Iratxeta C, Andrade-Navarro MA (2008) BMC Structural Biology 8: 25 .
Robertson BC, Zydney AL (1990) J. Colloid Interface Sci. 134: 563-575.

Rzigalinski BA (2005) Technol. Cancer Res. Treat. 4: 651-659.

Shang W, Nuffer JH, Dordick JS, Siegel RW (2007) Nano Lett. 7: 1991-1995.

Tok J, Boey F, Dong Z, Sun XL (2007) J. Mater. Process Technol. 190: 217-222.

Toth J (2002) Marcel Dekker, Sci. Ser. Toxicon. 107: 971-983.

Walczyk D, Bombelli FB, Monopoli MP, Lynch I, Dawson KA (2010) J. Am. Chem. Soc. 132: 5761-5768.

Wang B, Wu P, Yokel RA, Grulke EA (2012) Influence of surface charge on lysozyme adsorption to ceria nanoparticles. Appl. Surface Sci. 258: 5332-5341.

Wu X, Narsimhan G (2008) Langmuir 24: 4989-4998. 